\title{
EFFECTIVENESS OF CHLORHEXIDINE AS A CAVITY DISINFECTANT IN ATRAUMATIC RESTORATIVE TREATMENT IN PRIMARY TEETH ( A RANDOMIZED CONTROLLED CLINICAL TRIAL)
}

\author{
Lina AR Matar ${ }^{1}$ BDs, Karin ML Dowidar 2Phd, Dalia M Talaat 3Phd, Dina A kholeif 4Phd, \\ Hams H Abdelrahman5Msc.
}

\begin{abstract}
INTRODUCTION: Since the removal of caries in the Atraumatic restorative treatment (ART) is performed with hand excavation, its survival would increase if more bacteria could be inhibited under the restoration. The use of antibacterial agents such as Chlorhexidine gluconate (CHX) was found to hinder the growth of bacteria under restorations, reducing the risk of recurrent caries.

OBJECTIVE: Evaluate the effectiveness of $\mathrm{CHX}$ as a cavity disinfectant, on residual cariogenic bacteria, in ART restorations.

MATERIALS AND METHODS: Atraumatic restorative treatment procedures were performed to the whole sample ( $\mathrm{N}=40$ ), with identical protocols except for the antibacterial agent used. Bacteriological samples from the center of the cavity were cultivated for Mutans streptococci (MS), Lactobacilli (LB) and total viable count (TVC). Chlorhexidine was applied onto the cavity floor in group I (N=20) and conventional ART without disinfectant was performed in group II $(\mathrm{N}=20)$. After 14 days, the restorations were removed and a second dentin sample was cultivated for bacteriologic assessment of the outcome.

RESULTS: After 14 days, Group I showed 22.17, 8.25, 6.88 mean percent reduction of MS, LB, and TVC, respectively whereas group II showed 12.67, 6.87, 6.11 mean percent reduction of MS, LB, TVC, respectively. MS and LB showed significantly higher percent reduction in group I compared to group II. Moreover, group I showed higher mean percent reduction in TVC than group II; however, it was not statistically significant. CONCLUSION: Chlorhexidine disinfection showed superior effectiveness in inhibiting residual bacteria under ART restoration compared to ART restorations using glass ionomer cement (GIC) alone.
\end{abstract}

KEY WORDS: Atraumatic restorative treatment, chlorhexidine, primary teeth

RUNNING TITLE: Chlorhexidine usage as a cavity disinfectant in atraumatic restorative treatment.

1 B.D.S. Faculty of Dentistry Alexandria University

2 Professor of Pediatric Dentistry, Pediatric Dentistry and Dental Public Health Department, Faculty of Dentistry Alexandria University

3 Assistant Professor of Pediatric Dentistry, Pediatric Dentistry and Dental Public Health Department, Faculty of Dentistry Alexandria University

4 Lecturer of Medical Microbiology and Immunology Medical Microbiology and Immunology Department Faculty of Medicine Alexandria University

5 Assistant Lecturer of dental public health, Pediatric Dentistry and Dental Public Health Department, Faculty of Dentistry Alexandria University

* Corresponding Author:

Email: linamatar1989@hotmail.com

\section{INTRODUCTION}

Dental caries is regarded as the most prevalent chronic disease that affects children. Consequently, dental caries, in developed and developing countries, poses as a major oral health problem. The prevention and control of dental caries is attained by the elimination of the cariogenic bacteria that produce acids, as these acids cause a decrease in the $\mathrm{pH}$ and consequently starts the process of demineralization (1). The carious lesion management can better be achieved utilizing a more biological or medical model of treatment rather than the previously adopted surgical approach. The new approach for dental caries management focuses on the maximum removal of bacteria from the carious lesion while maintaining minimum tooth tissue loss and minimum patient discomfort.
This new treatment modality is known as minimal intervention dentistry (MID) (2).

Atraumatic restorative treatment (ART) is a part of the therapeutic armamentarium of MID. It involves removing the soft, demineralized and carious tooth tissues solely with the use hand instruments. This is followed by the restoration of the cavity using an adhesive dental material that simultaneously acts as a sealant to the remaining pits and fissures. Therefore, ART procedure comprises a preventive component (ART sealant) and an operative component (ART restoration) (3).

Despite the fact that ART was initially created for the underserved communities, ART is being utilized now in developed countries and private practices for the management 
of caries in children (4). This approach eliminated the need to use local anesthesia as it uses only hand instruments, which also disposed the need to use rotary instruments that caused uncomfortable vibrations. ART is therefore considered to be a patient-friendly approach, offering a good alternative for the introduction of restorative care to young and uncooperative children (5).

Nevertheless, the ART procedure has its limitations such as operator fatigue and decreased accessibility which can lead to incomplete excavation (6,7). Moreover, secondary caries and restoration failure may result from the residual bacteria left unintentionally under a restoration. Therefore, the concept of utilizing antibacterial agents came into play (1).

The literature reveals that chlorhexidine (CHX) is an efficient chemotherapeutic agent that contributes to the reduction of residual bacteria after cavity excavation (8). It is forseen as the gold standard antimicrobial agent due to its broad spectrum antimicrobial action that provides it with the ability to inhibit a wide range of gram positive and gram negative bacteria (9).

Studies proved that chlorhexidine exhibited antibacterial effects against Mutans streptococci (MS) and Lactobacillus (LB) without affecting the physical properties of the glass ionomer material (10). However, it has been reported that an interaction may occur between the CHX antibacterial agent and the fluoride ions component of the GICs, causing an interference with the antibacterial effect of the GIC restoration (11). Hoszek and Ericson (12) indicated that the addition of CHX disinfectants to GICs contributes to the antibacterial properties of the material. Nonetheless, they noted that the fluoride ion release may decrease, interfering with the antibacterial effect of the restoration. Further research is needed to determine whether adding CHX to the ART procedure would benefit the antibacterial effect of GIC or not.

In light of the aforementioned account, this study was conducted to evaluate in vivo the cavity disinfectant effectiveness of CHX on the residual cariogenic bacteria in primary molars undergoing ART approach. The null hypothesis presented is that there will be no difference in the residual bacteria, whether the ART cavity is filled with GIC alone, or disinfected with CHX then filled with GIC.

\section{METHODS}

\section{Ethical clearance and consent}

Prior to conducting the study, ethical clearance (IORG000839) was obtained from the Research Ethics Committee, Faculty of dentistry, Alexandria University, Egypt. The objectives, risks and benefits of the study were explained to parents/ guardians and a signed informed consent was obtained before treatment. All the possible clinical and /or adverse outcomes were explained to parents and they were asked to report immediately if any of them occurred. All children were given instructions regarding oral hygiene procedures and received dental care.

This study was a two-armed randomized controlled clinical trial. It was set up and reported according to the CONSORT statement (13). (Identifier: NCT03855527-clinical trial.gov). The PICOT question was: do primary teeth undergoing ART (population; P) using Chlorhexidine cavity disinfectant (intervention; I) in comparison to traditional ART without a disinfecting agent (control; C) show same residual bacteria in the dentinal tubules (outcome; O) after 14 days (time; T).

\section{Study participants}

Patients included in this study were selected by residents from the outpatient clinic, Pediatric dentistry and Dental public health department, Faculty of dentistry, Alexandria university, Egypt, from February 2018 to January 2019. Patients were treated in the postgraduate clinic of the same faculty. Patients were 4-6 years old, cooperative children (Frankl scale 3 and 4) (14) and free from any systematic diseases or special health care needs. The teeth included in the study were primary molars presenting with class I occlusal cavity involving the dentin (International Caries Detection and Assessment System 5 or 6) (15). Lesions had no proximal caries as detected by radiographic examination. The lesions were accessible for hand excavation (16). Teeth presenting with any clinical or radiographic signs of irreversible pulpitis and/or pulp necrosis were excluded from the study. Intraoral periapical radiographs were performed for the confirmation of the diagnosis and for the exclusion of pulpal or apical pathology, on the one hand, and for the reassurance that no continuity between the carious lesion of the selected tooth and its pulp chamber was detected, on the other (17).

\section{Sample size estimation (18)}

Total sample size of 40 patients was estimated based on the following assumptions: confidence level $=95 \%$ and study power $=80 \%$. The reduction in mean (SD) of log transformed TVC after 2 weeks for CHX was 3.93 (0.85) (19), and 3.15 (0.865) for GIC (20). The final sample was calculated to be 20 patients per group.

\section{Randomization and Allocation concealment}

Subjects complying with the inclusion criteria were randomly assigned by block randomization, the block size of 4 , using a computer generated list. The participants were randomly divided into two groups (Group I: $(n=20)$ ART with CHX cavity disinfection, Group II: $(n=20)$ ART without cavity disinfection).

Allocation was performed by the statistician using sequentially numbered opaque sealed envelopes and the allocation ratio was intended to be equal. The operator was not blinded to the type of treatment as each antibacterial agent had different consistency, color and application techniques. The expert assessing the microbiological sample and statistician were blinded to the treatment groups, as each sample Eppendorf was given a code number only known to the investigator and revealed at the end of the study.

\section{Intervention \\ Calibration}

The sampling procedure was practiced on extracted teeth before carrying out the study, and the samples were weighed by the main operator to ensure that dentin samples of similar amounts were obtained from the sampling sites.

Participants were assigned to the intervention. All the ART restorations and dentinal sample collection for microbial analysis were performed by a single operator. Carious lesions removal was done using ART technique according to the recommendations described by Frencken et al. (3). 
Topical anesthesia was applied around the tooth to be isolated and rubber dam was placed to avoid contamination with saliva during sampling. The tooth surface was cleaned with the use of a wet cotton pellet to remove debris. Cavity opening enlargement was performed if needed with the aid of a sterile hatchet. The carious dentin was removed with an excavator (Hu-Friedy 131/132, 14-9-8, USA) to the point where firm dentin was reached (physically resistant to hand excavation) (21). In this study we used the tactile criteria, the probe does not stick in dentin and does not give a tug-back sensation (22)

The baseline dentin sample was collected with a sterile spoon excavator from the firm dentin, situated at the center of the cavity and transferred into Eppendorf tubes containing $0.5 \mathrm{ml}$ of phosphate buffer solution (23). It was given a number and transported immediately to the bacteriology laboratory at the Faculty of Medicine, Alexandria University, Egypt, for microbiological analysis.

- Clinical photographs of the sampling site were taken for the identification of the same central sampling site during the second dentin sample for sampling site standardization (24).

- For dentin sample standardization, the sample was taken with the same sized excavator for all cases; the amount of the dentin removed was just sufficient to cover the surface of the excavator (25).

- Cavity depth measurements were performed with the aid of a sterilized endodontic file for depth standardization during sampling. The measurement was transferred to a sterilized endodontic ruler and recorded (26). This procedure guided the later removal of restorative material and collection of the test sample.

In Group I, cavities were disinfected by placing a cotton pellet soaked in CHX (2\% chlorhexidine (Consepsis, Ultradent) (1)) solution for 1 minute, air dried and restored using glass ionomer cement (16).

In Group II, cavities were restored directly using glass ionomer cement (GC Fuji IX).

In both groups, cavities were temporary restored with glass ionomer cement handled according to manufacturer's instructions. Cavity conditioning was not performed in order to make sample collection easier following the experimental period (26).

Second dentin sample: Patients were recalled after 14 days. Clinical examination was performed and the patients were asked if any symptoms occurred during the previous 14 days. Using the previously recorded location and depth as a reference point, the restoration was removed using air rotor for initial access under rubber dam, and the deepest layer was removed by cleaving the GIC with a manual instrument, thus it as possible to avoid inadvertent removal of the dentin adjacent to the GIC (26) and a second dentin sample was collected for analysis as previously mentioned.

Cavity conditioning was done for 10 seconds using cotton pellet. Cavities were rinsed thoroughly with water and the excess was blotted away with a cotton pellet taking into consideration not to desiccate the cavity as the prepared surfaces should appear moist. The same steps for glass ionomer restoration were followed and the teeth were definitively restored with the same material.

\section{Study Outcomes}

Assessing the change in the TVC, MS and LB count.

\section{Microbiological procedure}

The samples were serially diluted $(1: 10)$ in phosphate buffer saline. All the samples were inoculated with a lawn culture method on blood agar for Total Viable Count (TVC), and mitis salivarius agar (M259-500G, HiMedia) supplemented with 15 percent sucrose and bacitracin $(0.2 \mathrm{U} / \mathrm{ml})$ for selective isolation of Mutans Streptococci (MS), and Rogosa agar (M130-500G, HiMedia), a medium selective for Lactobacilli (LB).The plates were incubated anaerobically in an atmosphere containing 10 percent $\mathrm{CO}_{2}$ (AnaeroGen 2.5L) at $37 \mathrm{C}^{\circ}$ for 72 hours in an atmosphere of $10 \%$ hydrogen, $10 \%$ carbon dioxide and $80 \%$ nitrogen generated through the hydration of single use anaerobic gas pack. Following the predetermined incubation periods, the Bacterial count of TVC, MS and LB were recorded as colonyforming units (CFUs) per milliliter (16). The change in the bacterial count between the first sample (baseline) and second sample (after 14 days) was documented for the assessment of the study outcome.

\section{Statistical analysis}

The Log bacterial counts were calculated to normalize the data. Normality was checked using Shapiro Wilk test, TVC and LB showed a normal distribution while MS displayed a non-normality. The difference in TVC and LB means was tested using Student's test "parametric test" whereas MS means and percent reduction were compared using Mann Whitney test "non-parametric test". The differences in bacterial count, before and after treatment, was assessed using paired $\mathrm{t}$ test and its non-parametric counterpart, Wilcoxon Signed Rank test. For adjusting baseline variability and ensuring comparability between groups, change from each group baseline was calculated using percent change according to the following formula: [(count after-count before)/ count before) $\times 100]$. Significance level was set at $p \leq$ 0.05 . Data was analyzed using IBM SPSS statistical software (version 25).

\section{RESULTS}

Forty children who met the inclusion criteria were included in this study. In the CHX group, the mean age was $(4.90 \pm 0.58)$, $50 \%$ of the enrolled sample were males while $50 \%$ were females. In the GIC group, the mean age was (4.93 \pm 0.69$)$ years, $55 \%$ of the enrolled sample were males while $45 \%$ were females. No statistical significant difference was detected between the two groups regarding age and gender ( $\mathrm{P}$ value 0.902 , 0.961 respectively). (Table1)

Table 1: Demographic variables (Age and gender) 


\begin{tabular}{|c|c|c|c|c|}
\hline \multicolumn{2}{|c|}{ Variables } & $\begin{array}{c}\text { Group I } \\
\text { (CHX group) } \\
(\mathrm{n}=20)\end{array}$ & $\begin{array}{l}\text { Group II } \\
\text { GIC group } \\
(\mathrm{n}=20)\end{array}$ & $P$ value \\
\hline \multicolumn{2}{|l|}{ Age: Mean (SD) } & $4.90(0.58)$ & $4.93(0.69)$ & $0.902^{\mathrm{a}}$ \\
\hline \multirow[t]{2}{*}{ Gender: $\mathrm{n}(\%)$} & Male & $10(50 \%)$ & $11(55 \%)$ & \multirow{2}{*}{$0.961^{b}$} \\
\hline & Female & $10(50 \%)$ & $9(45 \%)$ & \\
\hline
\end{tabular}

a. Student t test

b. Pearson Chi-Square test

CHX: Chlorohexidine

GIC: Glass ionomer cement

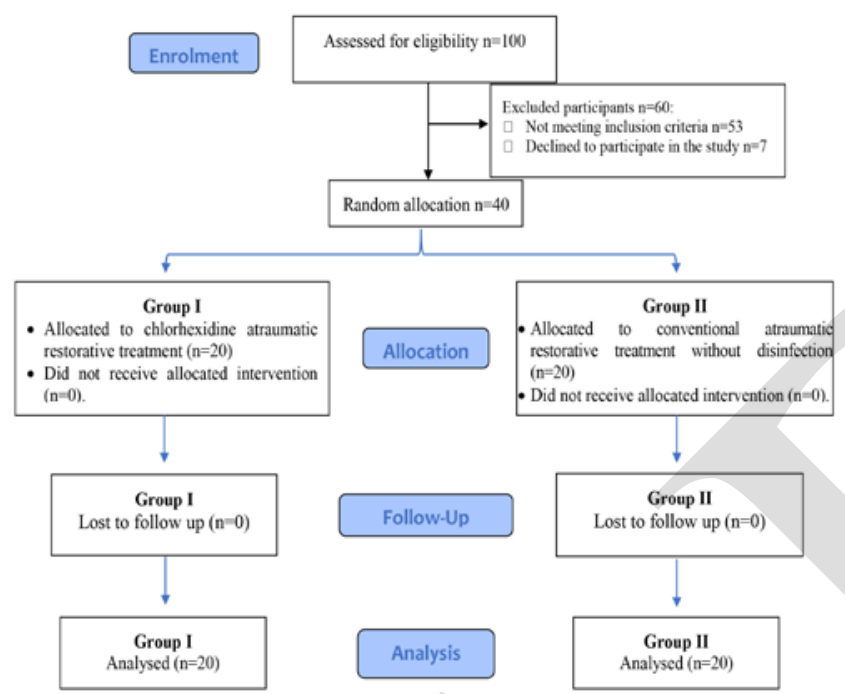

Figure 1: A CONSORT flow diagram

The baseline (sample one) mean $\log _{10}$ value for TVC, MS and LB in group I was 5.41, 4.39, 4.97, respectively while after 14 days it was 5.04, 3.42,4.56, respectively, revealing a statistically significant decrease for all the tested bacteria in this group $(\mathrm{P}<0.0001)$. (Table 2$)$

The baseline (sample one) mean $\log _{10}$ value for TVC, MS and LB in group II was 5.42, 4.49, 5.21, respectively, while after 14 days it was 5.09, 3.94, 4.85, respectively, also revealing a statistically significant decrease for all the tested bacteria in this group $(\mathrm{P}<0.0001)$. (Table 2$)$

Table 2: Comparison between group I (CHX group) and group II (GIC group) regarding log10 values of TVC, MS and LB.

\begin{tabular}{|c|c|c|c|c|c|c|c|c|c|}
\hline & \multicolumn{3}{|c|}{$\begin{array}{c}\text { Total viable count } \\
\log _{10} \mathrm{CFU} / \mathrm{ml}\end{array}$} & \multicolumn{3}{|c|}{$\begin{array}{c}\text { Mutans Streptococci } \\
\log _{10} \mathrm{CFU} / \mathrm{ml}\end{array}$} & \multicolumn{3}{|c|}{$\begin{array}{c}\text { Lactobacilli } \\
\log _{10} \mathrm{CFU} / \mathrm{ml}\end{array}$} \\
\hline & $\begin{array}{c}1^{\text {s }} \\
\text { sample }\end{array}$ & $\begin{array}{c}2^{\text {nd }} \\
\text { sample } \\
\end{array}$ & \multirow[t]{2}{*}{$P$ value ${ }^{a}$} & $\begin{array}{c}1^{s /} \\
\text { sample }\end{array}$ & $2^{\text {sid }}$ sample & \multirow{2}{*}{$P$ value $^{b}$} & $\begin{array}{c}1^{\text {st }} \\
\text { sample }\end{array}$ & $\begin{array}{c}2^{\text {sid }} \\
\text { sample }\end{array}$ & \multirow[t]{2}{*}{$P$ value ${ }^{a}$} \\
\hline & \multicolumn{2}{|c|}{ Mean (SD) } & & \multicolumn{2}{|c|}{ Mean (SD) } & & Mean & (SD) & \\
\hline $\begin{array}{l}\text { Group I } \\
\text { (CHX group) }\end{array}$ & $\begin{array}{c}5.41 \\
(0.16) \\
\end{array}$ & \begin{tabular}{|c|}
5.04 \\
$(0.21)$ \\
\end{tabular} & $<0.0001^{*}$ & $\begin{array}{c}4.39 \\
(0.26)\end{array}$ & 3.42 (1.19) & $<0.0001^{*}$ & $\begin{array}{c}4.97 \\
(0.26)\end{array}$ & $\begin{array}{c}4.56 \\
(0.23)\end{array}$ & $<0.0001^{*}$ \\
\hline $\begin{array}{l}\text { Group II } \\
\text { (GIC group) }\end{array}$ & $\begin{array}{c}5.42 \\
(0.16) \\
\end{array}$ & $\begin{array}{c}5.09 \\
(0.29) \\
\end{array}$ & $<0.0001^{*}$ & $\begin{array}{c}4.49 \\
(0.26) \\
\end{array}$ & $3.94(0.95)$ & $<0.0001^{*}$ & $\begin{array}{c}5.21 \\
(0.29) \\
\end{array}$ & $\begin{array}{c}4.85 \\
(0.31)\end{array}$ & $<0.0001^{*}$ \\
\hline$P$ value & $0.87^{\circ}$ & $0.52^{\mathrm{c}}$ & & $0.22^{d}$ & $<0.0001^{* d}$ & & $0.009^{* c}$ & $0.002^{* c}$ & \\
\hline $\begin{array}{l}\text { *St } \\
\text { a. P } \\
\text { b. } \\
\text { c. S } \\
\text { d. } \\
\text { CH } \\
\text { GIC }\end{array}$ & $\begin{array}{l}\text { tistically si } \\
\text { aired } t \text { test } \\
\text { illcoxon Si } \\
\text { udent } t \text { test } \\
\text { lann Whitn } \\
\text { X: Chlorol } \\
\text { Glass ior }\end{array}$ & $\begin{array}{l}\text { ignificant d } \\
\text { igned Rank } \\
\text { hexidine } \\
\text { nomer cen }\end{array}$ & $\begin{array}{l}\text { ifference at } \\
\text { test } \\
\text { tent }\end{array}$ & 5 & & & & & \\
\hline
\end{tabular}

By comparing the two groups, regarding the TVC, no statistical significance was found between group I and group II (P value 0.52) while the results for the MS and LB were significantly lower in group I when compared to their respective microbial counts in group II ( $\mathrm{P}$ value $<0.0001$, 0.002 , respectively). (Table 2 )

The mean percent reduction of the TVC, MS and LB for group I was $(6.88 \pm 2.12,22.17 \pm 27.03,8.25 \pm 1.68)$ while the mean percent reduction of the TVC, MS and LB for group II was $(6.11 \pm 3.49,12.67 \pm 20.75,6.87 \pm 1.86)$. By comparing the two groups the TVC did not reveal statistical significance $(\mathrm{P}=$ 0.11 ), however, MS and LB showed significantly more percent reduction in group I than group II after 14 days $(\mathrm{P}=0.001,0.02$, respectively). (Table 3 )

Table 3: Comparison between group I (CHX group) and group II (GIC group) regarding percent reduction in TVC, MS and LB count.

\begin{tabular}{|c|c|c|c|}
\hline & Total viable count & $\begin{array}{c}\text { Mutans } \\
\text { Streptococci }\end{array}$ & Lactobacilli \\
\hline Group I (CHX group) & $6.88(2.12)$ & $22.17(27.03)$ & $8.25(1.68)$ \\
\hline Group II (GIC group) & $6.11(3.49)$ & $12.67(20.75)$ & $6.87(1.86)$ \\
\hline value $^{\mathrm{a}}$ & 0.11 & $0.001^{*}$ & $0.02^{*}$ \\
\hline \hline
\end{tabular}

*Statistically significant difference at $p$ value $\leq 0.05$

a. Mann Whitney U test

\section{DISCUSSION}

The objective of this study was to evaluate the effectiveness of CHX cavity disinfectant in the reduction of the residual bacteria underneath ART restoration. Based on the results of our study the null hypothesis was rejected.

The ART technique possesses an antibacterial effect due to the sealing capacities of the filling material. This material acts as a physical barrier that stops the exogenous nutrients necessary for growth from reaching the bacteria under the GIC restoration (27). However, hand excavation alone does not remove carious dentin effectively, since this technique may unintentionally leave a residual layer of carious dentin and cariogenic bacteria may survive under GIC restorations (28). The TVC at the baseline, revealed the presence of bacteria in all tested samples, therefore, our results, in agreement with other studies $(1,29,30)$, revealed incomplete bacterial elimination with hand excavation only.

Glass ionomer cement is the material of choice that has traditionally been utilized for the ART technique due to its 
ability of fluoride release, its chemical adhesion to the tooth structure, and ease of use. Despite the GIC capability of discharging fluoride, which provides a significant antibacterial property and favours the reminerlization of dentin, still the reduction of the bacterial count obtained by placing GIC alone is not reliable for the ART restorations (31). This is attributed to the fact that researchers have found that the fluoride released from GIC was sometimes insuffecient to prevent secondary cases $(32,33)$. Therefore, pretreatment of the cavity surface using an antibacterial agent in the ART technique, is regarded as a useful method to eleminate harmful effect caused by residual bacteria (16).

Although the ART technique did not need complete isolation, a rubber dam was used in this study to avoid contamination with saliva during sampling as any salivary contamination would affect the bacterial count (16). Since the method of sample collection may have an influence on the accuracy of the number of bacteria isolated from a specific site, a reliably standardized method was used in this study by taking dentin samples with the same sized sterile spoon excavator. This method was selected for the current study because it is rendered as an atraumatic technique that reduces the risk of accidental exposure. In addition, the samples loss is not expected, contrary to the bur method where the bur rotation may cause scatter of the dentin particles (22).

Pretreatment of the ART cavity preparation utilizing an antibacterial agent provides the advantage of decreasing the number of the residual bacteria left under the ART restoration, and hence decreasing the risk of recurrent caries and pulp damage (16). Chlorohexidine have been recognized as the gold standard antibacterial agent in dentistry due its potent action against bacteria (34) which originates from the ability of the CHX molecule to disrupt the bacterial cell membrane increasing the cell permeability and resulting in its lysis (35). In the current study, 2\% chlorhexidine gluconate-based cavity disinfectant was used, this concentration does not alter the adhesion of the restorative materials to dentin (36). Yetkiner et al proved that the use of $2 \%$ chlorhexidine-based cavity disinfectant did not impair the adhesion of the glass ionomer to either sound or caries-affected dentin (37).

In the present study, the mean percent reduction of the TVC for group I (CHX group) was higher than group II (GIC group) but the difference between them was not statistically significant. These results were in agreement with studies performed by Wicht et al (38) and Borges et al (19). They suggested that using a bigger sample, might reflect a more significant effect on the TVC by CHX.

Regarding the MS, group I (CHX group) exhibited significantly more reduction than group II (GIC group) after 14 days. This indicated that the addition of CHX disinfectant to Fuji IX GIC resulted in a restorative material with enhanced antimicrobial properties over Fuji IX alone. Chimata et al (39) also demonstrated the superior effect of CHX addition to Fuji IX against Fuji IX alone. They regarded the fluoride leached from GIC as the most probable reason for its antibacterial effect. These results also coincided with studies performed by Frencken et al (40) and Joshi et al (16) that proved that adding $\mathrm{CHX}$ to GIC had a superior effect in inhibiting residual microorganisms.
In the current study, the mean percent reduction of LB in group I (CHX group) was also higher than group II (GIC group). These results are in accordance with previous studies by Kabil et al (17) and Frencken et al (40) that showed that the addition of CHX to GIC was significantly effective in inhibiting LB beneath GIC.

The results obtained for lactobacilli are not in contrast with those found by Borges et al. (19). They were evaluating the effect of $2 \%$ CHX cavity disinfectant on demineralized dentin. They could not demonstrate a significant superior effect of CHX on LB. It should be noted that in the current study, the microbiological analysis was performed two weeks after $\mathrm{CHX}$ application while Borges et al. performed it after a 5 minutes period (19). Moreover, our study followed an in vivo methodology unlike the in situ methodology used by Borges et al., which may have contributed to the different results between the two studies.

The use of CHX cavity preparation disinfection in our study was more effective in reducing residual cariogenic bacteria under ART restoration. Although the use of $\mathrm{CHX}$ does not completely eradicate the viable microorganisms, it still serves an effective agent for inhibiting the residual bacteria in ART preparation, which would enhance the survival of the restoration.

The main limitation of the present study was the very short follow-up period; it was difficult to assess the superiority of CHX disinfection over GIC on the TVC. Another limitation to this study is that significant differences appeared at baseline in the LB count between the two groups. Therefore, bacterial quantification data that was documented from each carious lesion were compared before and after the treatment in order to assess the effect of the test agent within the individual.

Results of the current study revealed that CHX was effective in reducing the residual bacteria left under a restoration improving the long term prognosis of the performed restoration (19).

\section{CONCLUSION}

This study demonstrated significantly more reduction in the MS and LB count in the ART group performed with chlorhexidine cavity disinfection, therefore, it was concluded that CHX improves the antimicrobial action of the ART restoration against residual bacterial and could pose as an alternative to traditional ART performed with GIC alone.

\section{CONFLICT OF INTEREST}

The authors declare that they have no conflicts of interest. The authors received no specific funding for this work.

\section{REFERENCES}

1. Article O. Role of herbal agents - tea tree oil and aloe vera as cavity disinfectant adjuncts in minimally invasive dentistry- An in vivo comparative study. J Clin Diagn Res. 2017;11:5-9.

2. Rao A, Malhotra N. The role of remineralizing agents in dentistry: a review. Compend Contin Educ Dent. 2011;32:26-33.

3. Frencken JE, Pilot T, Songpaisan Y, Phantumvanit P. Atraumatic Restorative Treatment (ART): Rationale, Technique, and Development. Dent Abstr. 2014;59:e21. 
4. Honkala E, Behbehani J, Ibricevic H, Kerosuo E, Al-Jame $\mathrm{G}$. The atraumatic restorative treatment (ART) approach to restoring primary teeth in a standard dental clinic. Int $\mathrm{J}$ Paediatr Dent. 2003;13:172-9.

5. Garg Y, Bhaskar DJ, Suvarna M, Singh N, Lata S, Bose $\mathrm{S}$. Atraumatic restorative t reatment in dentistry. Int J Oral Heal Med Res. 2015;2:126-9.

6. Groen HJ. The residual caries dilemma. Community Dent Oral Epidemiol. 1999;27:436-41.

7. Yip HK, Smales RJ, Ngo HC, Tay FR, Chu FCS. Selection of restorative materials for the atraumatic restorative treatment (ART) approach: A review. Spec Care Dent. 2001;21:216-21.

8. Botelho MG. Inhibitory effects on selected oral bacteria of antibacterial agents incorporated in a glass ionomer cement. Caries Res. 2003;37:108-14.

9. Balagopal S, Arjunkumar R. Chlorhexidine: The gold standard antiplaque agent. J Pharm Sci Res. 2013;5:270-4.

10. Türkün LS, Türkün M, Ertug rul F, Ates M, Brugger S. Long-term antibacterial effects and physical properties of a chlorhexidine-containing glass ionomer cement. J Esthet Restor Dent. 2008;20:29-44.

11. Palmer G, Jones FH, Billington RW, Pearson GJ. Chlorhexidine release from an experimental glass ionomer cement. Biomaterials. 2004;25:5423-31.

12. Hoszek A, Ericson D. In vitro fluoride release and the antibacterial effect of glass lonomers containing chlorhexidine gluconate. Oper Dent. 2008;33:696-701.

13. Schulz KF, Altman DG, Moher D. CONSORT 2010 Statement: Updated guidelines for reporting parallel group randomised trials. BMJ. 2010;340:698-702.

14. Stigers JI. Nonpharmacologic Management of Children's Behaviors. In: Dean JA, McDonald RE, Avery DR, Jones JE, Vinson LA (eds). McDonald and Avery's Dentistry for the Child and Adolescent. $10^{\text {th }}$ ed. St. Louis, Missouri: Elsevier Mosby; 2016. pp 286-302.

15. Ladewig NM, Sahiara CS, Yoshioka L, Olegário IC, Floriano I, Tedesco TK, et al. Efficacy of conventional treatment with composite resin and atraumatic restorative treatment in posterior primary teeth: study protocol for a randomised controlled trial. BMJ Open. 2017;7:e015542.

16. Joshi JS, Roshan MDSNM, Sakeenabi MDSB, Poornima P, Nagaveni MDSNB, Subbareddy MDSV V. Inhibition of residual cariogenic bacteria in atraumatic restorative treatment by chlorhexidine: Disinfection or incorporation. Pediatr Dent. 2017;39:308-12.

17. Kabil NS, Badran AS, Wassel MO. Effect of the addition of chlorhexidine and miswak extract on the clinical performance and antibacterial properties of conventional glass ionomer: an in vivo study. Int $\mathrm{J}$ Paediatr Dent. 2017;27:380-7.

18. Faul F, Erdfelder E, Lang A-G, Buchner A. G*Power 3: a flexible statistical power analysis program for the social, behavioral, and biomedical sciences. Behav Res Methods. 2007;39:175-91.

19. Borges FM, De Melo MA, Lima JP, Zanin IC, Rodrigues LK. Antimicrobial effect of chlorhexidine digluconate in dentin: In vitro and in situ study. J Conserv Dent. 2012;15:22-6.
20. Wicht MJ, Haak R, Schütt-Gerowitt H, Kneist S, Noack MJ. Suppression of caries-related microorganisms in dentine lesions after short-term chlorhexidine or antibiotic treatment. Caries Res. 2004;38:436-41.

21. Ricketts D, Landuyt K Van, Banerjee A, Campus G, Doméjean S. Managing carious lesions: Consensus recommendations on terminology. Adv Dent Res. 2016;28:49-57.

22. El-Tekeya M, El-Habashy L, Mokhles N, El-Kimary E. Effectiveness of 2 chemomechanical caries removal methods on residual bacteria in dentin of primary teeth. Pediatr Dent. 2012;34:325-30.

23. Uday Mohan PVM, Uloopi KS, Vinay C, Rao RC. In vivo comparison of cavity disinfection efficacy with APF gel, Propolis, Diode Laser, and 2\% chlorhexidine in primary teeth. Contemp Clin Dent. 2016;7:45-50.

24. Bjørndal L, Larsen T, Thylstrup A. A clinical and microbiological study of deep carious lesions during stepwise excavation using long treatment intervals. Caries Res. 1997;31:411-7.

25. Modimi KV, Siddaiah SB, Chikkanarasaiah N, Rucha V, Abubakar SB, Dinraj K, et al. Microbiological assessment of carious dentine using chemomechanical caries removal and conventional hand excavation in primary and permanent teeth: A clinical study. J Int Oral Heal. 2016;8:760-6.

26. Massara MLA, Alves JB, Branda PRG. Atraumatic restorative treatment: Clinical, ultrastructural and chemical. Caries Res. 2002;36:430-6.

27. Toi CS, Bönecker M, Cleaton-Jones PE. Mutans streptococci strains prevalence before and after cavity preparation during Atraumatic Restorative Treatment. Oral Microbiol Immunol. 2003;18:160-4.

28. Karched M, Ali D, Ngo H. In vivo antimicrobial activity of silver diammine fluoride on carious lesions in dentin. J Oral Sci. 2019;61:19-24.

29. Mohan PVMU, Uloopi K, Vinay C, Rao RC. In vivo comparison of cavity disinfection efficacy with APF gel, Propolis, Diode Laser, and 2\% chlorhexidine in primary teeth. Contemp Clin Dent. 2016;7:45-50.

30. Chimata VK, Yadiki JV, Jampanapalli SR, Konda S, Inguva HC. Comparative evaluation of the antimicrobial properties of glass ionomer cements with and without chlorhexidine gluconate. Int $\mathrm{J}$ Clin Pediatr Dent. 2016;9:99-103.

31. Deepalakshmi M, Poorni S, Miglani R, Rajamani I, Ramachandran S. Evaluation of the antibacterial and physical properties of glass ionomer cements containing chlorhexidine and cetrimide: An in-vitro study. Indian J Dent Res. 2010;21:552-6.

32. Mei ML, Zhao IS, Ito L, Lo EC-M, Chu C-H. Prevention of secondary caries by silver diamine fluoride. Int Dent J. 2016;66:71-7.

33. Burke FJ, Cheung SW, Mjör IA, Wilson NH. Reasons for the placement and replacement of restorations in vocational training practices. Prim Dent Care. 1999;6:17-20.

34. Hamama HH, Yiu CK, Burrow MF. Effect of silver diamine $\mathrm{fl}$ uoride and potassium iodide on residual bacteria in dentinal tubules. Aust Dent J. 2015;60:80-7. 
35. Balagopal S, Arjunkumar R. Chlorhexidine: The gold standard antiplaque agent. J Pharm Sci Res. 2013;5:270-4.

36. Aykut-Yetkiner A, Candan U, Ersin N, Eronat C, Belli S, Özcan M. Effect of $2 \%$ chlorhexidine gluconate cavity disinfectant on microtensile bond strength of toothcoloured restorative materials to sound and caries-Affected dentin. J Adhes Sci Technol. 2015;29:1169-77.

37. Aykut-Yetkiner A, Candan U, Ersin N, Eronat C, Belli S, Özcan M. Effect of $2 \%$ chlorhexidine gluconate cavity disinfectant on microtensile bond strength of toothcoloured restorative materials to sound and caries-affected dentin. J Adhes Sci Technol. 2015;29:1169-77.

38. Wicht MJ, Haak R, Schütt-Gerowitt H, Kneist S, Noack MJ. Suppression of caries-related microorganisms in dentine lesions after short-term chlorhexidine or antibiotic treatment. Caries Res. 2004;38:436-41.
39. Chimata VK, Yadiki JV, Jampanapalli SR, Konda S, Inguva HC. Comparative evaluation of the antimicrobial properties of glass ionomer cements with and without chlorhexidine gluconate. Int $\mathrm{J}$ Clin Pediatr Dent. 2016;9:99-103.

40. Frencken JE, Imazato S, Toi C, Mulder J, Mickenautsch S, Takahashi Y, et al. Antibacterial effect of chlorhexidine- containing glass ionomer cement in vivo: A pilot study. Caries Res. 2007;41:102-7. 